\title{
Leptomeningeal Carcinomatosis in a Patient with Pancreatic Cancer Responding to Nab-Paclitaxel plus Gemcitabine
}

\author{
Garry Ceccon $^{a} \quad$ Michael Wollring ${ }^{a}$ Anna Brunn ${ }^{b}$ Martina Deckert ${ }^{b}$ \\ Dirk Waldschmidtc, e Gereon R. Fink ${ }^{a}$, $d$ Norbert Galldiks ${ }^{a}$ d, e \\ aDepartment of Neurology, Faculty of Medicine and University Hospital Cologne, University \\ of Cologne, Cologne, Germany; bepartment of Neuropathology, Faculty of Medicine \\ and University Hospital Cologne, University of Cologne, Cologne, Germany; 'Department \\ of Hepato- and Gastroenterology, Faculty of Medicine and University Hospital Cologne, \\ University of Cologne, Cologne, Germany; ${ }^{d}$ Institute of Neuroscience and Medicine \\ (INM-3), Forschungszentrum Jülich, Jülich, Germany; ${ }^{e}$ Center of Integrated Oncology (CIO), \\ Universities of Aachen, Bonn, Cologne, and Duesseldorf, Cologne, Germany
}

\section{Keywords}

Leptomeningeal metastasis · Carcinomatous meningitis · FOLFIRINOX · Blood-brain barrier

\begin{abstract}
Leptomeningeal carcinomatosis is an extremely rare, but devastating complication in pancreatic cancer patients with a poor prognosis despite multimodal treatment. We present a 51-year-old male patient with the very rare condition of leptomeningeal carcinomatosis originating from pancreatic cancer. He presented to our hospital with severe headache and neck stiffness 30 months after systemic chemotherapy. Cerebral and spinal MRI as well as cerebrospinal fluid examination confirmed the diagnosis of leptomeningeal carcinomatosis. The patient responded to gemcitabine plus nab-paclitaxel in terms of elimination of tumor cells from the CSF and concurrent clinical improvement for 3 months. The observed findings suggest that the combination of gemcitabine plus nab-paclitaxel is potentially effective in affected cerebrospinal fluid of pancreatic carcinoma patients.

\section{Background}

Leptomeningeal carcinomatosis (LC) is a very aggressive complication of solid tumors and hematologic malignancies and occurs in approximately $5-15 \%$ of all cancer patients [13]. Symptoms are unspecific and may vary according to the localization of the cancer cells in 

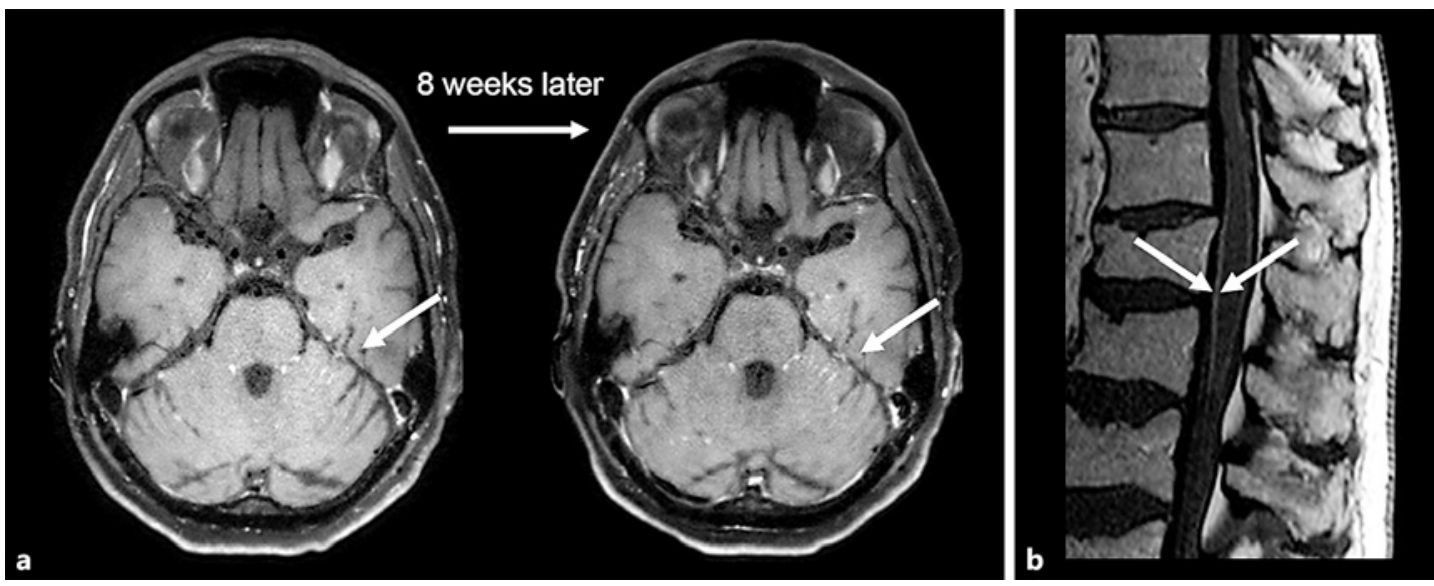

Fig. 1. a Contrast-enhanced cerebral MRI at baseline (left) with nodular and linear contrast enhancement in the cerebellum, consistent with leptomeningeal carcinomatosis. Follow-up MRI (right-hand side) shows a slight increase in contrast enhancement. b Contrast-enhanced spinal T1-weighted MRI of the spine (right) with leptomeningeal contrast enhancement.

the central nervous system. The most frequent clinical signs are headache, neck stiffness, changes in mental status, cranial nerve palsies, and spinal signs including dermatomal sensory loss, radicular pain, bowel and bladder dysfunction, and limb weakness [4, 5]. It predominantly occurs in breast and lung cancer as well as in melanoma [6]. Diagnosis is confirmed by the neuropathological examination of the cerebrospinal fluid (CSF) and contrast-enhanced MRI of the brain and spine. Usually, MRI shows leptomeningeal contrast enhancement [7, 8]. Subependymal deposits, nodular enhancement and hydrocephalus may also be seen. Most common CSF findings are pleocytosis of variable extent, high protein and lactate concentration, hypoglycorrhachia, elevated opening pressure, and, most importantly, presence of cancer cells $[1,4]$. Not infrequently, to identify cancer cells, multiple lumbar punctures are required [9]. Despite aggressive treatment, prognosis remains dismal. Median survival is only within the range of weeks without treatment $[6,10,11]$ and several months in patients undergoing multimodal treatment including systemic therapy, radiotherapy and intrathecal chemotherapy [12-16]. Thus, novel therapeutic options are urgently needed. Here, we present a patient with the extremely rare condition of LC secondary to pancreatic cancer who showed treatment response to nab-paclitaxel plus gemcitabine.

\section{Case Description}

A 51-year-old male patient with abdominal pain for several months was diagnosed with pancreatic cancer (Ca 19-9 and CK7 positive, CDX2 negative). At initial diagnosis, the left kidney and the spleen were already infiltrated by the tumor (UICC stadium IVB). Furthermore, $\mathrm{X}$-ray examination of the thorax suggested multiple lung metastases. Due to the infiltration of the adjacent abdominal organs, complete surgical resection was not possible. Thus, first-line treatment consisted of gemcitabine plus erlotinib according to the RASH trial [17]. Thirteen months later, chemotherapy was changed to the FOLFIRINOX regimen (leucovorin, 5 -fluorouracil, irinotecan, oxaliplatin) due to local tumor progression. Following the second-line FOLFIRINOX regimen, the patient was stable for further 17 months. Thirty-two months after initial diagnosis of pancreatic cancer, the patient presented with severe headache. Neuro- 
Fig. 2. CSF findings: clusters of epithelial tumor cells with enlarged, hyperchromatic nuclei and a small cytoplasm. Note prominent mucoid cytoplasmic vacuoles leading to signet ring cells (arrow). Pappenheim staining; original magnification $\times 400$. Insert: the tumor cells express CK7. Immunohistochemistry with mouse anti-human cytokeratin 7 (DCS, Hamburg, Germany); original magnification $\times 500$.

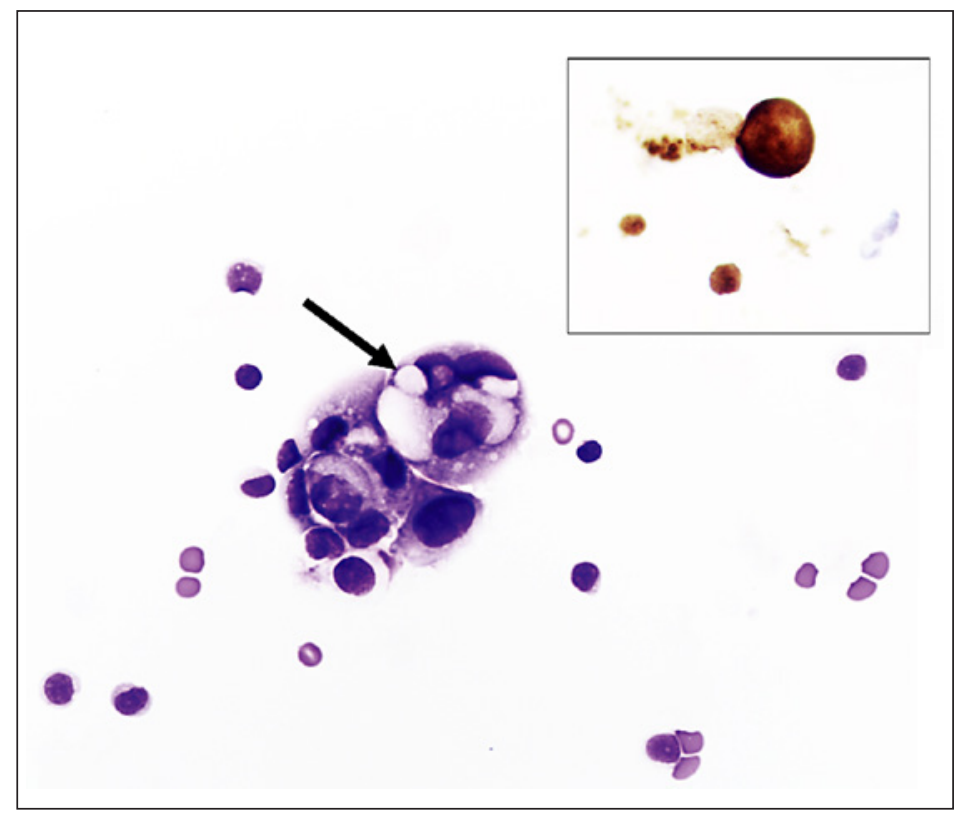

logical examination revealed neck stiffness without further neurological deficits. Cerebral and spinal contrast-enhanced MRI showed leptomeningeal enhancement (Fig. 1); lumbar puncture revealed elevated protein $(0.52 \mathrm{~g} / \mathrm{dL})$, low glucose $(42 \mathrm{mg} / \mathrm{dL})$, increased lactate ( $3.9 \mathrm{mmol} / \mathrm{L})$, and a mild pleocytosis $(23$ cells $/ \mu \mathrm{L})$. CSF cytology revealed clusters of enlarged, pleomorphic epithelial cells harboring large nuclei and prominent cytoplasmic vacuoles, frequently corresponding to "signet ring cells" (Fig. 2). The tumor cells were intermingled with reactive inflammatory cells consisting of lymphocytes and macrophages. Immunohistochemistry of the CSF detected CK7-positive cells, thus, yielding the diagnosis of LC due to an adenocarcinoma (Fig. 2).

However, the patient refused treatment escalation to radiotherapy and intrathecal chemotherapy. Instead, he consented to change the systemic treatment regimen to nab-paclitaxel plus gemcitabine. After a few weeks, the patient's condition improved substantially. Headache and neck stiffness vanished almost completely. In addition, CSF cell count had declined to 12 cells/ $\mu \mathrm{L}$ and cancer cells were no longer detectable. However, follow-up cerebral MRI showed a slight increase in leptomeningeal contrast enhancement (Fig. 1).

Upon the patient's request, treatment was continued with nab-paclitaxel and gemcitabine, without applying intrathecal chemotherapy or adding radiotherapy. Notwithstanding, 3 months later, his condition deteriorated rapidly with palsies of cranial nerves III, IV, VI, and VII, gait disorder and, finally, disturbed consciousness despite systemic chemotherapy with nab-paclitaxel and gemcitabine. The patient died 35 months after the diagnosis of pancreatic cancer, and 3 months after diagnosis of LC.

\section{Discussion and Conclusions}

In our patient with unresectable pancreatic cancer, LC was diagnosed when systemic disease had been stable for 32 months following systemic chemotherapy. After initiation of treatment with gemcitabine plus nab-paclitaxel, the clinical symptoms and CSF findings improved substantially and the patient lived for further 3 months, although follow-up MRI 
was slightly progressive. This case is remarkable in two ways. First, only 15 cases of LC in pancreatic cancer have been published so far [18-32]. Most of the patients described in these case reports were male and more than 50 years old, matching the characteristics of our patient. Nearly all of them rapidly deteriorated clinically and died soon after LC was diagnosed. However, in 2 cases, a longer survival has been reported. The patient reported by Hirota et al. [22] lived approximately 3.5 years after the diagnosis of LC. In that case, LC seemed to have completely dissolved following whole brain radiotherapy, and the patient finally died from progressive systemic disease. It remains unclear why whole brain radiotherapy was so efficient in this single patient. More recently, Johnson et al. [32] observed a patient in whom survival of approximately 10 months could be achieved using multimodal chemotherapy including capecitabine, irinotecan, intrathecal topotecan, and bevacizumab. These data underline the extreme rarity but also the severity of LC secondary to pancreatic cancer; patients usually do not survive more than a few weeks.

Second, a clear clinical response could be achieved following treatment with gemcitabine and nab-paclitaxel, which was also accompanied by an improvement of pleocytosis and removal of adenocarcinoma cells from the CSF. Treatment of LC with CSF involvement usually consists of radiotherapy of the brain and spine, accompanied by systemic chemotherapy and intrathecal application of chemotherapeutic agents. Frequently used drugs for intrathecal chemotherapy are methotrexate, cytarabine and thiotepa [12-14, 33]. However, due to possible severe side effects and the necessity of repeated hospitalization, the patient refused an aggressive treatment regimen. Thus, in the present case, treatment was changed to gemcitabine and nab-paclitaxel.

In the last few years, nanoparticle albumin-bound paclitaxel (nab-paclitaxel) is increasingly being used in patients with breast cancer and non-small-cell lung cancer. In contrast to standard formulations of taxanes (e.g., paclitaxel and docetaxel), nab-paclitaxel is associated with fewer hypersensitivity reactions and with better penetration into cancer cells [34-39]. In addition to greater efficacy and a favorable safety profile compared to standard paclitaxel in these cancer types [37, 40], the use of gemcitabine plus nab-paclitaxel in patients with pancreatic cancer has also been reported to lead to an improved response rate as well as longer progression-free and overall survival when compared to gemcitabine monotherapy $[41,42]$. The main reason for this superiority seems to be a better penetration of nab-paclitaxel into the tumor. One possible mechanism could be binding of albumin by SPARC (secreted protein acidic and rich in cysteine). This glycoprotein is often overexpressed in different types of tumors, leading to a better response to nab-paclitaxel by transferring the drug into the extravascular space $[43,44]$. Other studies have discussed SPARC-independent ways such as the gp60 albumin receptor pathway. Binding of albumin to this glycoprotein seems to lead to the forming of transcytotic vesicles and delivering nab-paclitaxel into the cancer cells [45-48].

Many chemotherapeutic agents are considered ineffective for treating LC due to their limited ability to cross the blood-brain barrier (BBB). According to the literature, the combination of gemcitabine and nab-paclitaxel seems not very promising. For gemcitabine, data are ambiguous. One study showed that less than $10 \%$ penetrate into the central nervous system [49]. In a rat model, Apparaju et al. [50] observed a relative brain distribution coefficient of $<0.1$, indicating no relevant penetration of the BBB. However, considerably higher values were measured in the brain tumor relative to tumor-free regions of the brain in that study. This was attributed to a more permeable tumor vasculature. On the other hand, Sigmond et al. [51] administered gemcitabine to patients prior to brain biopsy, and, subsequently, detected relevant concentrations in the bioptic samples. Thus, it remains questionable whether gemcitabine reaches the central nervous system in a sufficient concentration. For nab-paclitaxel, data are even more scarce. While paclitaxel is known to have a poor BBB pene- 
Table 1. Overview of reports addressing leptomeningeal carcinomatosis in pancreatic cancer

\begin{tabular}{|c|c|c|c|c|c|}
\hline Study & $\begin{array}{l}\text { Age, } \\
\text { years }\end{array}$ & Gender & Chemotherapy & $\begin{array}{l}\text { RT } \\
\text { performed }\end{array}$ & Survival \\
\hline Galatioto et al. [18], 1975 & n.r. & n.r. & n.r. & n.r. & n.r. \\
\hline Kurzaj et al. [19], 1980 & 36 & M & No & No & $\begin{array}{l}\text { Few weeks, } \\
\text { not specified }\end{array}$ \\
\hline Ferreira et al. [20], 2001 & 49 & M & $\begin{array}{l}\text { Thiotepa } \\
\text { Methotrexate } \\
\text { Cytarabine }\end{array}$ & No & 8 weeks \\
\hline Grira et al. [21], 2007 & 55 & M & No & No & 7 weeks \\
\hline Hirota et al. [22], 2008 & 64 & M & Gemcitabine & Yes & 3.5 years \\
\hline Rebischung et al. [23], 2008 & 44 & $\mathrm{~F}$ & $\begin{array}{l}\text { Methotrexate and } \\
\text { intrathecal }{ }^{125} \mathrm{IUdR}\end{array}$ & No & 6 months \\
\hline Minchom et al. [24], 2010 & 59 & M & $\begin{array}{l}\text { Methotrexate } \\
\text { Cytarabine } \\
\text { Gemcitabine }\end{array}$ & No & 6 weeks \\
\hline Blows et al. [25], 2012 & 72 & M & No & No & $\begin{array}{l}\text { Few weeks, } \\
\text { not specified }\end{array}$ \\
\hline Anne et al. [26], 2013 & 45 & $\mathrm{~F}$ & No & No & Rapid death \\
\hline Rao et al. [27], 2013 & 57 & M & FOLFIRINOX & Yes & n.r. \\
\hline Naqvi and Ahmed [29], 2015 & 58 & $\mathrm{~F}$ & No & No & 7 days \\
\hline Yoo et al. [30], 2015 & 80 & M & No & Yes & n.r. \\
\hline Trinh et al. [31], 2016 & 58 & M & No & No & 34 days \\
\hline Hong et al. [28], 2014 & 72 & $\mathrm{~F}$ & $\begin{array}{l}\text { Pelareorep } \\
\text { Carboplatin } \\
\text { Paclitaxel }\end{array}$ & No & 8 weeks \\
\hline Johnson et al. [32], 2018 & 53 & M & $\begin{array}{l}\text { Capecitabine } \\
\text { Irinotecan } \\
\text { Topotecan } \\
\text { Bevacizumab }\end{array}$ & Yes & 45 weeks \\
\hline
\end{tabular}

n.r., not reported; RT, radiotherapy; ${ }^{125}$ IUdR, 5-iodo-2'-deoxyuridine labeled with 125-I; FOLFIRINOX, folinic acid, 5-fluorouracil, irinotecan, and oxaliplatin.

tration [52], only one study in a mouse model evaluated the uptake of nab-paclitaxel in the brain [53]. Here, nab-paclitaxel only accumulated at low levels in the brain indicating that it cannot cross the BBB. In conclusion, due to the limited ability to cross the BBB, the combination of gemcitabine and nab-paclitaxel seems to be ineffective for LC treatment.

Remarkably, despite the issues discussed concerning BBB crossing, our patient showed rapid clinical improvement when gemcitabine and nab-paclitaxel were administered. He lived for 3 months after the diagnosis of LC, which exceeds survival of most pancreatic cancer patients with LC published so far (Table 1). One possible explanation for treatment efficacy could be the local impairment of the BBB. In brain metastases secondary to breast cancer, Lockman et al. [54] could demonstrate partial permeability of the BBB, but the uptake of ${ }^{14} \mathrm{C}$-doxorubicin and ${ }^{14} \mathrm{C}$-paclitaxel into brain metastases were less than $15 \%$ compared to 
other tissues. In LC, the same phenomenon has been described [55]. One might argue that the described improvements in our patient were not related to treatment. However, when looking at the devastating clinical courses of LC despite treatment - with a median survival of several weeks $[6,10,11]$ - this seems very unlikely.

In conclusion, the present case suggests possible efficacy of gemcitabine plus nab-paclitaxel in a patient with LC secondary to pancreatic cancer. Further data are necessary to confirm our observations.

\section{Statement of Ethics}

Written informed consent for publication of this case report and associated images could not be obtained from the patient because of reduced consciousness. Informed written consent to publish data and images was obtained from the patient's wife.

\section{Disclosure Statement}

The authors declare that they have no competing interests.

\section{Funding Sources}

No funding to declare.

\section{Author Contributions}

G.C. and N.G. made the conception and design of the paper, interpretation of data, and drafted the manuscript. G.C., M.W., A.B., M.D., and D.W. made substantial contribution to the acquisition and analysis of data. G.R.F. was involved in critically revising the manuscript for important intellectual content. All authors read and approved the final manuscript.

\section{References}

1 Kaplan JG, DeSouza TG, Farkash A, Shafran B, Pack D, Rehman F, et al. Leptomeningeal metastases: comparison of clinical features and laboratory data of solid tumors, lymphomas and leukemias. J Neurooncol. 1990 Dec; 9(3):225-9.

2 Chamberlain MC. Neoplastic meningitis. Curr Neurol Neurosci Rep. 2008 May;8(3):249-58.

3 Groves MD. Leptomeningeal disease. Neurosurg Clin N Am. 2011 Jan;22(1):67-78, vii.

4 Clarke JL, Perez HR, Jacks LM, Panageas KS, Deangelis LM. Leptomeningeal metastases in the MRI era. Neurology. 2010 May 4;74(18):1449-54.

5 Clarke JL. Leptomeningeal metastasis from systemic cancer. Continuum (Minneap Minn). 2012 Apr;18(2): 328-42.

6 Wasserstrom WR, Glass JP, Posner JB. Diagnosis and treatment of leptomeningeal metastases from solid tumors: experience with 90 patients. Cancer. 1982 Feb 15;49(4):759-72.

7 Collie DA, Brush JP, Lammie GA, Grant R, Kunkler I, Leonard R, et al. Imaging features of leptomeningeal metastases. Clin Radiol. 1999 Nov;54(11):765-71.

8 Singh SK, Leeds NE, Ginsberg LE. MR imaging of leptomeningeal metastases: comparison of three sequences. AJNR Am J Neuroradiol. 2002 May;23(5):817-21.

9 Glantz MJ, Cole BF, Glantz LK, Cobb J, Mills P, Lekos A, et al. Cerebrospinal fluid cytology in patients with cancer: minimizing false-negative results. Cancer. 1998 Feb 15;82(4):733-9.

10 Chamberlain MC, Tsao-Wei D, Groshen S. Neoplastic meningitis-related encephalopathy: prognostic significance. Neurology. 2004 Dec 14;63(11):2159-61. 
Ceccon et al.: Leptomeningeal Carcinomatosis Secondary to Pancreatic Cancer

11 Waki F, Ando M, Takashima A, Yonemori K, Nokihara H, Miyake M, et al. Prognostic factors and clinical outcomes in patients with leptomeningeal metastasis from solid tumors. J Neurooncol. 2009 Jun;93(2):205-12.

12 Hitchins RN, Bell DR, Woods RL, Levi JA. A prospective randomized trial of single-agent versus combination chemotherapy in meningeal carcinomatosis. J Clin Oncol. 1987 Oct;5(10):1655-62.

13 Grossman SA, Finkelstein DM, Ruckdeschel JC, Trump DL, Moynihan T, Ettinger DS. Randomized prospective comparison of intraventricular methotrexate and thiotepa in patients with previously untreated neoplastic meningitis. Eastern Cooperative Oncology Group. J Clin Oncol. 1993 Mar;11(3):561-9.

14 Glantz MJ, Jaeckle KA, Chamberlain MC, Phuphanich S, Recht L, Swinnen LJ, et al. A randomized controlled trial comparing intrathecal sustained-release cytarabine (DepoCyt) to intrathecal methotrexate in patients with neoplastic meningitis from solid tumors. Clin Cancer Res. 1999 Nov;5(11):3394-402.

15 Gauthier H, Guilhaume MN, Bidard FC, Pierga JY, Girre V, Cottu PH, et al. Survival of breast cancer patients with meningeal carcinomatosis. Ann Oncol. 2010 Nov;21(11):2183-7.

16 Park JH, Kim YJ, Lee JO, Lee KW, Kim JH, Bang SM, et al. Clinical outcomes of leptomeningeal metastasis in patients with non-small cell lung cancer in the modern chemotherapy era. Lung Cancer. 2012 Jun;76(3):387-92.

17 Haas M, Siveke JT, Schenk M, Lerch MM, Caca K, Freiberg-Richter J, et al. Efficacy of gemcitabine plus erlotinib in rash-positive patients with metastatic pancreatic cancer selected according to eligibility for FOLFIRINOX: a prospective phase II study of the 'Arbeitsgemeinschaft Internistische Onkologie'. Eur J Cancer. 2018 May; 94: 95-103.

18 Galatioto S, Savettieri G. [Meningeal carcinomatosis secondary to a primary pancreatic tumor. Anatomaclinical study]. Acta Neurol (Napoli). 1975 Jul-Aug;30(4):359-67.

19 Kurzaj E, Kopczynski S, Barowska-Lehman J, Ludwiczak R. Subdural haematoma associated with dural carcinomatosis in a patient with primary carcinoma of pancreas. Neurochirurgia (Stuttg). 1980 Jan;23(1):13-7.

20 Ferreira Filho AF, Cardoso F, Di Leo A, Awada A, da Silva VD, Tovar RB, et al. Carcinomatous meningitis as a clinical manifestation of pancreatic carcinoma. Ann Oncol. 2001 Dec;12(12):1757-9.

21 Grira MT, Ben Jemaa HM, Lammouchi TM, Benammou SA. Meningitis revealing pancreatic carcinoma. Neurosciences (Riyadh). 2007 Jul;12(3):256-8.

22 Hirota M, Yagi Y, Yamashita K, Okamoto K, Sato T, Ichihara T. [A long survival case of unresectable pancreatic cancer by chemoradiotherapy with gemcitabine as key drug]. Gan To Kagaku Ryoho. 2008 Dec;35(13):2413-6.

23 Rebischung C, Hoffmann D, Stefani L, Desruet MD, Wang K, Adelstein SJ, et al. First human treatment of resistant neoplastic meningitis by intrathecal administration of MTX plus (125)IUdR. Int J Radiat Biol. 2008 Dec;84(12):1123-9.

24 Minchom A, Chan S, Melia W, Shah R. An unusual case of pancreatic cancer with leptomeningeal infiltration. ] Gastrointest Cancer. 2010 Jun;41(2):107-9.

25 Blows SJ, Morgan R, Dhariwal U, Petts G, Roncaroli F. Pancreatic adenocarcinoma presenting with sudden onset bilateral deafness secondary to metastatic leptomeningeal infiltration. Age Ageing. 2012 Nov;41(6): 818-9.

26 Anne M, Ahmad N, Lee P, Aziz M, Lebowicz Y. An unusual presentation of isolated leptomeningeal disease in carcinoma of unknown primary with pancreatic features. J Investig Med High Impact Case Rep. 2013 Apr-Jun; 1(2):2324709613494830.

27 Rao R, Sadashiv SK, Goday S, Monga D. An extremely rare case of pancreatic cancer presenting with leptomeningeal carcinomatosis and synchronous intraparenchymal brain metastasis. Gastrointest Cancer Res. 2013 May;6(3):90-2.

28 Hong CS, Kurt H, Elder JB. Asynchronous leptomeningeal carcinomatosis from pancreatic cancer: a case report and review of the literature. Clin J Gastroenterol. 2014 Oct; 7(5):434-40.

29 Naqvi SA, Ahmed I. Carcinomatous meningitis: a rare complication of pancreatic adenocarcinoma. J Coll Physicians Surg Pak. 2015 Jun;25(6):458-9.

30 Yoo IK, Lee HS, Kim CD, Chun HJ, Jeen YT, Keum B, et al. Rare case of pancreatic cancer with leptomeningeal carcinomatosis. World J Gastroenterol. 2015 Jan 21;21(3):1020-3.

31 Trinh VT, Medina-Flores R, Chohan MO. Leptomeningeal carcinomatosis as primary manifestation of pancreatic cancer. J Clin Neurosci. 2016 Aug;30:124-7.

32 Johnson WR, Theeler BJ, Van Echo D, Young P, Kwok M. Treatment of leptomeningeal carcinomatosis in a patient with metastatic pancreatic cancer: a case report and review of the literature. Case Rep Oncol. 2018 May-Aug;11(2):281-8.

33 Boogerd W, van den Bent MJ, Koehler PJ, Heimans JJ, van der Sande JJ, Aaronson NK, et al. The relevance of intraventricular chemotherapy for leptomeningeal metastasis in breast cancer: a randomised study. Eur J Cancer. 2004 Dec;40(18):2726-33.

34 Robidoux A, Buzdar AU, Quinaux E, Jacobs S, Rastogi P, Fourchotte V, et al. A phase II neoadjuvant trial of sequential nanoparticle albumin-bound paclitaxel followed by 5 -fluorouracil/epirubicin/cyclophosphamide in locally advanced breast cancer. Clin Breast Cancer. 2010 Feb;10(1):81-6.

35 Yardley DA, Raefsky E, Castillo R, Lahiry A, Locicero R, Thompson D, et al. Phase II study of neoadjuvant weekly nab-paclitaxel and carboplatin, with bevacizumab and trastuzumab, as treatment for women with locally advanced HER2+ breast cancer. Clin Breast Cancer. 2011 0ct;11(5):297-305.

36 Kaklamani VG, Siziopikou K, Scholtens D, Lacouture M, Gordon J, Uthe R, et al. Pilot neoadjuvant trial in HER2 positive breast cancer with combination of nab-paclitaxel and lapatinib. Breast Cancer Res Treat. 2012 Apr; 132(3):833-42. 
Ceccon et al.: Leptomeningeal Carcinomatosis Secondary to Pancreatic Cancer

37 Socinski MA, Bondarenko I, Karaseva NA, Makhson AM, Vynnychenko I, Okamoto I, et al. Weekly nab-paclitaxel in combination with carboplatin versus solvent-based paclitaxel plus carboplatin as first-line therapy in patients with advanced non-small-cell lung cancer: final results of a phase III trial. J Clin Oncol. 2012 Jun 10; 30(17):2055-62.

38 Ricciardi GR, Russo A, Franchina T, Ferraro G, Adamo V. Efficacy of nab-paclitaxel plus trastuzumab in a longsurviving heavily pretreated HER2-positive breast cancer patient with brain metastases. Onco Targets Ther. 2015;8:289-94.

39 Ricciardi GR, Franchina T, Russo A, Schifano S, Ferraro G, Adamo V. Nab-paclitaxel and trastuzumab combination: a promising approach for neoadjuvant treatment in HER2-positive breast cancer. Onco Targets Ther. 2016;9:4351-5.

40 Gradishar WJ, Tjulandin S, Davidson N, Shaw H, Desai N, Bhar P, et al. Phase III trial of nanoparticle albuminbound paclitaxel compared with polyethylated castor oil-based paclitaxel in women with breast cancer. J Clin Oncol. 2005 Nov 1;23(31):7794-803.

41 Von Hoff DD, Ramanathan RK, Borad MJ, Laheru DA, Smith LS, Wood TE, et al. Gemcitabine plus nab-paclitaxel is an active regimen in patients with advanced pancreatic cancer: a phase I/II trial. J Clin Oncol. 2011 Dec 1; 29(34):4548-54.

42 Von Hoff DD, Ervin T, Arena FP, Chiorean EG, Infante J, Moore M, et al. Increased survival in pancreatic cancer with nab-paclitaxel plus gemcitabine. N Engl J Med. 2013 Oct 31;369(18):1691-703.

43 Desai N, Trieu V, Damascelli B, Soon-Shiong P. SPARC expression correlates with tumor response to albuminbound paclitaxel in head and neck cancer patients. Transl Oncol. 2009 May;2(2):59-64.

44 Neuzillet C, Tijeras-Raballand A, Cros J, Faivre S, Hammel P, Raymond E. Stromal expression of SPARC in pancreatic adenocarcinoma. Cancer Metastasis Rev. 2013 Dec;32(3-4):585-602.

45 Hawkins MJ, Soon-Shiong P, Desai N. Protein nanoparticles as drug carriers in clinical medicine. Adv Drug Deliv Rev. 2008 May 22;60(8):876-85.

46 Neesse A, Frese KK, Chan DS, Bapiro TE, Howat WJ, Richards FM, et al. SPARC independent drug delivery and antitumour effects of nab-paclitaxel in genetically engineered mice. Gut. 2014 Jun;63(6):974-83.

47 Hidalgo M, Plaza C, Musteanu M, Illei P, Brachmann CB, Heise C, et al. SPARC expression did not predict efficacy of nab-paclitaxel plus gemcitabine or gemcitabine alone for metastatic pancreatic cancer in an exploratory analysis of the phase III MPACT trial. Clin Cancer Res. 2015 Nov 1;21(21):4811-8.

48 Kim H, Samuel S, Lopez-Casas P, Grizzle W, Hidalgo M, Kovar J, et al. SPARC-independent delivery of nab-paclitaxel without depleting tumor stroma in patient-derived pancreatic cancer xenografts. Mol Cancer Ther. 2016 Apr;15(4):680-8.

49 Stukov AN, Filatova LV, Latipova D, Bespalov VG, Belyaeva OA, Kireeva GS, et al. [Therapeutic activity of gemcitabine in intracranial tumors]. Vopr Onkol. 2015;61(2):274-9.

50 Apparaju SK, Gudelsky GA, Desai PB. Pharmacokinetics of gemcitabine in tumor and non-tumor extracellular fluid of brain: an in vivo assessment in rats employing intracerebral microdialysis. Cancer Chemother Pharmacol. 2008 Feb;61(2):223-9.

51 Sigmond J, Honeywell RJ, Postma TJ, Dirven CM, de Lange SM, van der Born K, et al. Gemcitabine uptake in glioblastoma multiforme: potential as a radiosensitizer. Ann Oncol. 2009 Jan;20(1):182-7.

52 Fellner S, Bauer B, Miller DS, Schaffrik M, Fankhanel M, Spruss T, et al. Transport of paclitaxel (Taxol) across the blood-brain barrier in vitro and in vivo. J Clin Invest. 2002 Nov;110(9):1309-18.

53 Castellon M. Role of caveolae mediated transport for abraxane uptake in vivo. Graduate college: University of Illinois at Chicago; 2011; p. 34.

54 Lockman PR, Mittapalli RK, Taskar KS, Rudraraju V, Gril B, Bohn KA, et al. Heterogeneous blood-tumor barrier permeability determines drug efficacy in experimental brain metastases of breast cancer. Clin Cancer Res. 2010 Dec 1;16(23):5664-78.

55 Siegal T, Sandbank U, Gabizon A, Mizrachi R, Ben-David E, Catane R. Alteration of blood-brain-CSF barrier in experimental meningeal carcinomatosis. A morphologic and adriamycin-penetration study. J Neurooncol. 1987;4(3):233-42. 